\title{
FUNDAMENTACIÓN Y DETERMINACIÓN DE LA PENA EN EL DERECHO PENAL DE ADOLESCENTES. A PROPÓSITO DEL JUICIO SEGUIDO CONTRA B. N. M. POR DELITO DE ROBO CON INTIMIDACIÓN (RUC 0900505404-1) EN LA V REGIÓN***
}

\author{
Francisco Maldonado Fuentes**
}

\section{El Fallo}

Por sentencia de fecha 3 de noviembre de 2009 el Tribunal Oral en lo Penal de Viña del Mar condenó a B.N.M. a la pena de 5 años y un día de internación en régimen cerrado con programa de reinserción social por la comisión, en calidad de autor, de un delito consumado de robo con intimidación, realizado en la ciudad de Quilpué el 31 de mayo del mismo año.

Contra dicha sentencia se dedujo recurso de nulidad a ser resuelto por la Iltma. Corte de Apelaciones de Valparaíso, fundado -conforme a los argumentos de la defensa- en que la sentencia no daría cuenta de las exigencias de fundamentación requeridas, particularmente en relación a los factores o criterios que deben ser tenidos en cuenta para la determinación de la pena, apoyándose en la causal contenida en el art. 374 letra e) del CPrP'1 Subsidiariamente se alega una errónea aplicación del derecho (art. 374 letra b) del mismo Código), en base a que, en este caso concreto, y considerando la particular conducta de los adolescentes, no debió aumentarse la sanción penal en la aplicación del art. 21 de la Ley 20.084 (incremento fundado en la acreditación de las agravantes de pluralidad de mal

* Abreviaturas usadas en el texto: art.: artículo; CP: Código Penal; CPrP: Código Procesal Penal; H.L.: Historia de la Ley inc.: inciso; p.: página; pp.: páginas. Asimismo, se hace presente que en cada oportunidad en que el texto haga referencia a artículos o disposiciones sin indicar a qué cuerpo pertenecen, la referencia debe entenderse hecha a la Ley 20.084. Colaboración recibida el 19 de agosto y aprobada el 20 de septiembre de 2011.

** El documento ha sido elaborado en base a un comentario preparado para Microjuris.com, publicado en dicho sitio con la cita MJD421.

*** Abogado; Doctor en Derecho por la Universidad Pablo de Olavide (Sevilla); Profesor conferenciante de la Facultad de Derecho de la Universidad de Talca; Subdirector del Centro de Estudios de Derecho Penal de la misma Universidad. Correo electrónico: frmaldonado@utalca.cl.

1 En relación con el artículo 342 letra c) y d), ambas disposiciones del CPrP y 24 y 26 de la Ley 20.084 
hechores o de reincidencia específica), atendido el contexto y contenido material de la responsabilidad especial que regula dicho cuerpo legal.

Al respecto, la sentencia de nulidad (de fecha 15 de diciembre de 2009) desestima rápidamente $-y$ con escasa fundamentación- la primera alegación, acogiendo sin embargo la segunda, razonando en este último caso de manera particular sobre el fondo de las cuestiones ahí planteadas. En consecuencia, anula la sentencia recurrida condenando a N.M. (en la sentencia de reemplazo) a la pena de tres años y un día de internación en régimen cerrado con programa de reinserción social, sanción dos años inferior a la impuesta en el juicio oral. Dicha sanción, en concreto, se fundamenta en una mecánica de determinación de la pena que no considera la aplicación de las circunstancias modificatorias de responsabilidad penal (señaladas anteriormente) y que le sirvieren al Tribunal a quo para elevar el rango de la pena base en la fase primaria de determinación de la pena. Se arriba a dicha conclusión a partir de un razonamiento centrado en las particulares condiciones que plantea la adolescencia, presupuesto que se entiende y describe como un motivo que lleva a darles un tratamiento especial y distinto del concedido a los adultos en la ley penal, y de la cual el juez no puede prescindir a la hora de resolver. Este fundamento le daría un significado diverso a la reiteración delictiva y a la actuación en grupos, que les priva del efecto agravatorio que le atribuye la ley penal general.

Posteriormente, el 14 de junio de 2010, la Corte Suprema de Justicia, en uso de sus facultades disciplinarias, consideró que los Ministros de la Corte de Apelaciones de Valparaíso que participaron en el acuerdo han incurrido en falta o abuso calificada como grave, en razón a lo cual anula la sentencia que resuelve el recurso de nulidad y la respectiva sentencia de reemplazo, ordenando que se lleve a cabo una nueva vista de dicho recurso por una sala integrada por Ministros no inhabilitados.

Finalmente, se realiza la nueva vista del recurso rechazando el Tribunal de nulidad las dos causales invocadas, estableciendo primero que el sentenciador de la instancia razona adecuadamente acerca de los fundamentos para determinar la pena $y$, adicionalmente, que en dicho razonamiento no han incurrido en error de derecho.

\section{ARGUMENTACIÓN Y ANÁLISIS}

Del contenido de las resoluciones resumidas se desprenden varias cuestiones interesantes de analizar. En este caso nos limitaremos a abordar las siguientes:

Primero, la necesidad de determinar cuáles son las exigencias de fundamentación que pesan sobre la sentencia en lo relativo a la determinación de la pena, en especial, a qué debe referirse; cuál es el grado de desarrollo que ésta debe contener en la argumentación relativa a la fijación de la pena; y, parti- 
"Fundamentación y determinación de la pena en el derecho penal de adolescentes. A propósito del juicio seguido contra B. N. M. por delito de robo con intimidación (RUC 0900505404-1) en la V Región"

cularmente, cuáles son los criterios que deben ser considerados para llevar a cabo la fundamentación; y

Segundo, la incidencia que se asigna a la particular caracterización que es propia de la adolescencia en el proceso de valoración de las exigencias de la responsabilidad penal abordadas en este caso, puntualmente, en relación al comportamiento en grupos o pandillas y la reiteración delictiva. En particular se trata de analizar los efectos que tienen en el proceso de determinación de la pena regulado en la Ley 20.084 las agravantes previstas en el número $3^{\circ}$ del artículo 456 bis. y en el art. $12 \mathrm{~N}^{\circ} 16$, ambos del CP.

Procederemos a revisar por separado cada una de estas cuestiones, siempre a propósito de lo resuelto en las diversas resoluciones dictadas en la sustanciación del caso citado. De esta forma nuestro objetivo no lleva a agotar el tratamiento de las temáticas planteadas sino a reflexionar acerca de los argumentos debatidos en el caso que se comenta.

\section{EXIGENCIAS DE FUNDAMENTACIÓN DE LA SENTENCIA}

\section{Cuestiones generales}

En primer lugar, corresponde que nos ocupemos de las exigencias de fundamentación que debe satisfacer la sentencia condenatoria en el proceso de individualización de la pena, cuestión que en este caso se motiva por la recurrente en cuanto sostiene que la resolución del Tribunal de instancia no da cuenta de los parámetros legales procedentes y necesarios de considerar, particularmente, aquellos que se incluyen en los arts. 24 y 26 de la Ley 20.084. Ello, en su concepto, daría lugar a un motivo de nulidad conforme lo dispone el art. 374 letra e) apoyándose (en lo pertinente ${ }^{2}$ ) en que el art. 342 letra d) del CPrP dispone que la sentencia deberá contener tanto "las razones legales o doctrinales que sirvieren para calificar jurídicamente cada uno de los hechos y sus circunstancias" como también aquellas que sirvan "para fundar el fallo". Dicha disposición debería en este caso sistematizarse e incardinarse con lo dispuesto en el art. 24 de a Ley 20.084 que establece un total de seis criterios que deben ser tenidos en cuenta para individualizar la pena en el marco de la responsabilidad penal adolescente ${ }^{3}$.

\footnotetext{
2 Resulta relevante destacar que la parte recurrente también hace referencia a las letras c) y e) del artículo 342 del CPrP, disposiciones que a simple vista no parecen ser determinantes en lo relativo a la causal invocada, esto es, en materia de fundamentación de la sentencia. Más discutible resulta el que al art. 26 de la Ley 20.084 le quepa en este caso algún papel, cuestión que por razones de espacio no abordaremos en esta oportunidad.

${ }^{3}$ En concreto: "a) La gravedad del ilícito de que se trate; b) La calidad en que el adolescente participó en el hecho y el grado de ejecución de la infracción; c) La concurrencia de circunstancias atenuantes o agravantes de la responsabilidad criminal; d) La edad del adolescente infractor; e) La extensión del mal causado con la ejecución del delito, y f) La idoneidad de la sanción para fortalecer el respeto del
} 
Se concluye de ello que el fallo debe hacerse cargo del desarrollo y análisis de cada uno de dichos criterios, acorde a las características fácticas del caso concreto que esté siendo analizado ${ }^{4}$, en cuanto se trata de "razones legales" que sirven de base a la ponderación judicial.

Al respecto lo primero a tener en cuenta es que a estas alturas resulta más o menos evidente que toda mecánica donde opera el razonamiento judicial es, en el fondo, un espacio que ha sido delegado al juez por parte del legislador para que éste proceda a valorar todas y cada una de las particularidades presentes en el caso concreto que está llamado a resolver. Se trata de una mecánica de delegación que, en buena medida, resulta forzada para el legislador, en atención a que el medio que le es propio (la ley) resulta muy amplio, abstracto y general para captar la multiplicidad, riqueza y variabilidad que presenta cada una de las realidades que pretende regular. De esta forma, resulta indispensable recurrir al establecimiento de dinámicas normativas o valorativas que le permitan al sentenciador captar dichos contenidos particulares y medir la relevancia concreta que detentan para al sistema normativo. Dicha valoración no es en todo caso libre, pues requiere (siempre) ajustarse a los parámetros que hayan sido definidos por el legislador como criterios orientativos de dicha apreciación.

Conviene tener en cuenta que la fijación de dichos criterios parece ser obligatoria para el legislador pues permite dotar a la resolución del aval democrático de que goza la ley y de una base de razonabilidad y objetividad que, a fin de cuentas, permite sostener que la decisión judicial, en estos casos, no es en modo alguno arbitraria, sino más bien discrecional ${ }^{5}$. De ahí que el apego que muestren las resoluciones judiciales a los parámetros que han sido descritos por el legislador resulta ser una cuestión esencial, que por lo mismo se entiende expresamente como una de las exigencias necesarias de incluir en la sentencia para, precisamente, fundar el fallo. No es extraño entonces que se trate de un requisito cuya omisión queda incluida entre los motivos que ameritan la anulación del fallo, como sostiene acertadamente la recurrente, al menos en cuanto exigencia de la sentencia ${ }^{6}$.

adolescente por los derechos y libertades de las personas y sus necesidades de desarrollo e integración social".

${ }^{4}$ Ello quiere decir que deberán considerarse sólo en la medida en que concurran los presupuestos que permiten valorarlas. Así por ejemplo si no concurren circunstancias modificatorias de responsabilidad penal, es claro que no será necesario desarrollar razonamiento alguno respecto a lo dispuesto en la letra c) del art. 24.

${ }^{5}$ Si bien en un contexto más amplio Accatino, Daniela: "La motivación de las sentencias. Genealogía y teoría", tesis para optar al grado de Doctor en Derecho, Universidad de Granada, Departamento de Filosofía del Derecho, Granada, 2005, pp. 274 y ss.

${ }^{6}$ En este mismo sentido, con mayor desarrollo, Medina Schulz, Gonzalo: "Sobre la determinación de la pena y el recurso de nulidad en la Ley 20.084 sobre responsabilidad penal adolescente", Documento de Trabajo $N^{\circ}$ 14, Unidad de Defensa Penal Juvenil, Defensoría Penal Pública, año 2008 (publicado posteriormente en REJ $N^{\circ} 11$ ), pp. 12 y ss. 
"Fundamentación y determinación de la pena en el derecho penal de adolescentes. A propósito del juicio seguido contra B. N. M. por delito de robo con intimidación (RUC 0900505404-1) en la V Región"

Se trata por lo demás de una exigencia general, esto es, aplicable al régimen general como al sistema penal especial que es propio de los adolescentes, sin que existan motivos que lleven a asignarle un papel preponderante o más relevante en alguno de dichos sistemas ${ }^{7}$.

El segundo aspecto a considerar por ello es que su contenido se traduce específicamente en que dicha resolución debe incluir en estos casos un razonamiento capaz de dar cuenta de que se consideraron los factores previstos por el legislador. Se trata por ende de algo más que la sola mención de los criterios legales (sea nominal o referencial), pero a la vez de algo menos que una concreta y específica línea de razonamiento ${ }^{8}$. Y es que no se debe evaluar en este punto (a propósito de esta exigencia) la corrección, asertividad u orientación de lo resuelto pues ello implicaría demandar una determinada conclusión que se considera correcta, acertada o adecuada, y no un razonamiento. De ahí que resulte irrelevante el que no se compartan las conclusiones de la argumentación o que, simplemente, se trate de un razonamiento diverso al que personalmente creamos procedente a partir de las características concretas del caso enjuiciado. Lo relevante es que la exposición razonada del Tribunal sea capaz de evidenciar que su resolución se ha fundado en los parámetros legales procedentes, y no es fruto de una apreciación estrictamente personal o arbitraria. De esta forma la exigencia se mide y satisface en base a la presencia de un desarrollo argumental autosustentable, esto es, uno que se puede afirmar a partir de los supuestos fácticos del caso y de los criterios legales aplicables.

Sobre esa base un tercer elemento a considerar es el hecho de que en materia penal (que es lo que nos convoca) esta forma de resolver es algo habitual. En efecto, dicha dinámica se le plantea al Tribunal en múltiples instancias de su resolución, haciéndose presente a la hora de valorar la prueba, en todos aquellos casos en que algunos de los supuestos de la responsabilidad penal han sido establecidos por el legislador en términos normativos (elementos normativos propiamente tales y elementos subjetivos del tipo, parámetros normativos de las causales de justificación, criterios valorativos presentes en las circunstancias modificatorias de la responsabilidad penal, etc.) y, finalmente, en el proceso

\footnotetext{
7 En caso de adolescentes esta exigencia suele cobrar un sentido especial, lo que no es sino la consecuencia de que se promueven sistemas de determinación de la pena centrados en la óptica de la individualización judicial de la pena. De esta forma, y en cuanto dicho ámbito se ve recargado de mecánicas de valoración discrecionales y regladas, constituye una exigencia más notoria en dicho contexto, pero que no por ello pasa a tener en éste una mayor importancia o nivel de exigencia que en el régimen general. A ello se refiere expresamente el art. 24 de la Ley 20.084: "el tribunal deberá atender, dejando constancia de ello en su fallo, a los siguientes criterios:"

${ }^{8}$ Oo. en Medina, "Sobre la determinación", cit. nota n. 6, pp. 26 y 27, quien entiende que esto último resulta exigible, y que, consecuentemente, el que el sentenciador se aparte de una interpretación precisa y determinada puede dar lugar a un error de derecho.
} 
de determinación de la pena, particularmente en la llamada individualización judicial de la misma. En efecto, lo normal es que en la fase de determinación legal de la pena el Tribunal se limite a constatar los presupuestos legales procedentes y aplicar los efectos previstos por el legislador, sirviéndonos de ejemplo las reglas contenidas en nuestro CP para tasar las modificaciones de pena que deben realizarse en casos de participación y las que emanan de los estadios incompletos de ejecución delictiva (arts. 51 a 54 del CP). Por el contrario, forman parte de la llamada individualización de la pena aquellos casos en que el propio sentenciador debe resolver acorde a criterios, como sucede con la valoración de una atenuante como muy calificada (art. 68 bis del CP) o con la dinámica prevista en el art. 69 del $\mathrm{CP}^{9}$.

En cada uno de esos casos, y eventualmente en cada una de las reglas concretas previstas en la ley, los criterios orientativos pueden ser diversos, ajustados o regulados específicamente acorde a los objetivos que se persiguen en cada institución. Así por ejemplo en la regla prevista en el art. 67 del CP el legislador ha determinado que el juez debe resolver los aumentos o rebajas de grado acorde al número y entidad de las circunstancias concurrentes, mientras que en el art. 69 se remite a estos mismos criterios (número y entidad de las circunstancias atenuantes y agravantes) y a la "mayor o menor extensión del mal producido por el delito"10.

De ahí la relevancia de tener en cuenta de forma específica cuáles son los criterios necesarios de considerar en cada uno de esos casos, pues son éstos, y no otros, los que deben estar presentes en la argumentación respectiva. En concreto debe existir argumentación, esta debe ser razonable y debe fundarse en los hechos acreditados en el proceso y en los criterios legales procedentes.

En este contexto es que debe ser analizada la objeción planteada por la recurrente en la primera causal de nulidad invocada. Específicamente la infracción provendría del hecho que el Tribunal no daría cuenta en su desarrollo de

\footnotetext{
${ }^{9}$ Al respecto Vid. Mañalich R., Juan Pablo: “¿Discrecionalidad en la determinación de la pena en caso de concurrencia de circunstancias atenuantes de la responsabilidad penal?", Informe en Derecho 2/2009, Departamento de Estudios, Defensoría Penal Pública (Noviembre de 2009), pp. 3 a 9.

10 Si se observa se trata de parámetros que cumplen una función equivalente a la que se exige a la hora de proceder a la ponderación de la prueba, dinámica que queda reservada a un razonamiento que no contraríe "los principios de la lógica, las máximas de la experiencia y los conocimientos científicamente afianzados". Art. 297 inc. primero del CPrP. Dicha disposición remarca en los incisos segundo y tercero la forma como se debe desarrollar la valoración, apuntando que "El tribunal deberá hacerse cargo en su fundamentación de toda la prueba producida, incluso de aquélla que hubiere desestimado, indicando en tal caso las razones que hubiere tenido en cuenta para hacerlo. La valoración de la prueba en la sentencia requerirá el señalamiento del o de los medios de prueba mediante los cuales se dieren por acreditados cada uno de los hechos y circunstancias que se dieren por probados. Esta fundamentación deberá permitir la reproducción del razonamiento utilizado para alcanzar las conclusiones a que llegare la sentencia".
} 
"Fundamentación y determinación de la pena en el derecho penal de adolescentes. A propósito del juicio seguido contra B. N. M. por delito de robo con intimidación (RUC 0900505404-1) en la V Región"

buena parte de los criterios que serían necesarios de considerar, respecto de los cuales se plantearía un vacío en la argumentación. En concreto se señala que "la Ley sobre Responsabilidad Penal del Adolescente, como las (sic) $<$ Reglas de Beijin>, fijan criterios obligatorios para el juez, en lo relativo a cómo determinar la gravedad del ilícito, la concurrencia de circunstancias atenuantes y agravantes, extensión del mal causado e idoneidad de la sanción para fortalecer el respeto por los adolescente y sus necesidades de desarrollo e integración social" criterios que no habrían sido considerados al momento de dictar sentencia.

\section{Contenido de la sentencia}

Hay que tener en cuenta que la resolución recurrida contiene un desarrollo argumentativo breve y preciso a la hora de determinar la pena aplicable a B. N., dando cuenta del siguiente procedimiento para arribar a la sanción: Inicialmente, el Tribunal aplica la rebaja de grado prevista en el art. 21 de la Ley 20.084 (considerando que se trata de un menor de edad), para luego modificar dicho rango, elevando a su vez en un grado la penalidad. Considera para ello que se han acreditado dos agravantes y ninguna atenuante, de forma tal que, conforme lo dispone el inciso quinto del art. $67^{11}$, aplicable en la especie conforme al mismo art. 21 de la Ley $20.084^{12}$, el Tribunal cuenta con dicha posibilidad. En este caso se justifica el uso de dicha facultad discrecional y privativa del Tribunal en atención a que el aumento en un grado "se estima más condigno con el actuar del acusado, el cual registra ya otro paso por el sistema penal adolescente, en particular, otro robo con intimidación, habiéndosele aplicado la sanción de Libertad Asistida Simple, medida que no fue suficiente para enmendar su actuar, reincidiendo en el delito de robo con intimidación [] lo que determina, a juicio del Tribunal, que deba ahora ser objeto de una medida de intervención mayor, a fin de lograr una real y efectiva resocialización no lograda antes, y fortalecer así el respeto del adolescente por los derechos y libertades de las personas y sus necesidades de desarrollo e integración social." ${ }^{13}$

Hay que tener presente que la pena prevista en la ley para el delito de robo con intimidación es presidio mayor en su grado mínimo a máximo. Al rebajar un grado (por la minoría de edad) desde el grado mínimo la sanción se fija tentativamente en presidio menor en su grado máximo, grado que luego

11 "Si hay dos o más circunstancias agravantes y ninguna atenuante, puede aplicar la pena superior en un grado."

12 "Para establecer la duración de la sanción que deba imponerse con arreglo a la presente ley, el tribunal deberá aplicar, a partir de la pena inferior en un grado al mínimo de los señalados por la ley para el ilícito correspondiente, las reglas previstas en el Párrafo 4 del Título III del Libro I del Código Penal, con excepción de lo dispuesto en el artículo 69 de dicho Código".

${ }^{13}$ Considerando Decimosexto de la sentencia. 
el Tribunal eleva en una unidad en uso de la facultad judicial recién aludida. Queda entonces fijada la pena base (producto de lo que la sentencia de la Corte Suprema denomina fase primaria de la determinación de la pena, regulada en el art. 21 de la Ley 20.084) en una sanción equivalente al presidio mayor en su grado mínimo.

Con ello, y de acuerdo a lo dispuesto en el art. 23 de la Ley 20.084, el Tribunal debe elegir la pena de entre las propuestas en el primer tramo de sanciones previstas por el legislador, tramo que en este caso en particular solo prevé una única posibilidad de condena: el internamiento en régimen cerrado con programa de reinserción social por un lapso de tiempo que va entre los 5 años y un día y los 10 años de duración.

De esta forma se trata de un caso en que las opciones judiciales de individualización quedan sólo reguladas respecto de la cuantía o duración de la pena, toda vez que su naturaleza queda predeterminada a partir del resultado de la mentada fase primaria de la determinación de la pena. En este caso el Tribunal procede a imponer dicha sanción en su rango mínimo, esto es, 5 años y un día de internamiento en régimen cerrado, sin que la resolución consigne razón alguna que avale dicha decisión.

\section{Reglamentación vigente: el sistema de determinación de la pena en la Ley 20.084}

Lo primero a tener en cuenta es que la Ley 20.084 distingue dos procesos diversos en la determinación de la pena, ambos, regulados especialmente en dicho cuerpo normativo ${ }^{14}$. El primero de dichos procesos, que suele asociarse

\footnotetext{
${ }^{14}$ Conviene apuntar desde ya que entendemos que buena parte de las observaciones críticas que hasta la fecha ha motivado el sistema de determinación de la pena consagrado en la Ley 20.084 emanan de una inadecuada conceptualización y sistematización. En concreto constituye un error entender que se trata de un modelo desarrollado a partir de la distinción entre reglas de determinación de la duración de la pena y, luego, de otras que afectan o inciden en su naturaleza (en este sentido Horvitz L., María Inés, "Determinación de las sanciones en la ley de responsabilidad penal juvenil y procedimiento aplicable", Revista del CEJ N 7, 2006, pp. 102 y ss.; SAN MARTIN, María Angélica, "Valoración de circunstancias concurrentes no constituye doble valoración prohibida, ni admite revisión vía recurso de nulidad: comentario fallo de la Corte de Apelaciones de Antofagasta. Recurso 62/2009", Revista Jurídica del Ministerio Público № 38, 2009, p. 296). Igualmente errónea es una aproximación que asume que la individualización de la pena propiamente adolescente se inicia ya en el texto del art. 21, aproximación que no advierte que recién a partir del art. 23 aparecen en el proceso los contenidos particulares que proponen las sanciones especiales previstas en la ley. Lo dicho se puede corroborar en Bustos RamiREZ, Juan, Derecho penal del Niño-adolescente. Estudio sobre la ley penal del adolescente, Ediciones Jurídicas de Santiago, 2007, pp. 60 y ss; Horvitz, cit., pp. 11 y ss; Matus AcuÑa, Jean Pierre, "Proposiciones respecto de las cuestiones no resueltas por la ley 20.084 en materia de acumulación y orden de cumplimiento de las penas", Ius et Praxis Año 14, No 2, p. 545 y en el Primer informe de la (denominada) "Comisión de expertos" En: http://www.paz ciudadana.cl/publs.php?show=CAT\&idCat=26 [visitado el ]. De ahí que nos parezca necesaria una adecuada sistematización que permita destacar funciones de cada etapa, a partir de lo cual se podrán alcanzar soluciones básicas y elementales para
} 
"Fundamentación y determinación de la pena en el derecho penal de adolescentes. A propósito del juicio seguido contra B. N. M. por delito de robo con intimidación (RUC 0900505404-1) en la V Región"

a lo que la ley denomina la extensión de la pena, y que se sindica en los fallos citados como fase primaria de la determinación de la pena concluye -según acabamos de apreciar en términos prácticos- con un rango de alternativas dispuestas al sentenciador de entre las reguladas en el art. 23 y se desarrolla en base a las reglas previstas en los arts. 21, 22 y el propio art. 23. Se trata en los hechos de una mecánica que busca determinar en forma precisa un marco penal configurado con sanciones propias de los adolescentes y que por ello equivale al proceso de determinación legal de la pena juvenil15.

Por su parte el segundo proceso, que la ley regula nominalmente a propósito de la selección de la naturaleza de la pena y que técnicamente corresponde a la individualización de la misma, permite al sentenciador escoger la sanción concreta que se deberá imponer a partir de las alternativas consideradas en el tramo respectivo, mecánica que se extiende -según la interpretación mas asentada ${ }^{16}$ tanto a la naturaleza de la pena como a su extensión (con excepción al primer tramo de sanciones, según acabamos de exponer) ${ }^{17}$. En concreto en esta etapa el juez debe proceder a regular ambas variables a partir de un procedimiento que se rige en plenitud por una mecánica discrecional de individualización razonada, orientado básicamente por los criterios previstos en el art. 24. Se trata de una fase donde se ponderan todos los elementos del delito, sus circunstancias y los antecedentes personales relevantes de considerar, para arribar a una condena precisa, proceso que se encuentra siempre y plenamente regido por valoraciones propias del régimen especial de adolescentes. Baste ver que esta fase se inicia con un abanico de sanciones especiales para adolescentes y termina con una mecánica centrada en la valoración de criterios especialmente considerados

la mayoría de las cuestiones críticas que hasta la fecha se han planteado a este respecto. Conviene finalmente apuntar que el déficit de sistematización denunciado también se hacen presente torno al sistema de determinación de la pena de adultos, limitándose la mayoría de la manualística a asumir su análisis en un nivel exegético. Por todos, Cury UrzúA, Enrique, Derecho Penal. Parte General, Ediciones Universidad Católica de Chile, $7^{\circ}$ Edición, Santiago, 2005, pp. 763 y ss.; EtcheberRY O. Alfredo, Derecho Penal. Parte General, $3^{\circ}$ Edición, Edit. Jurídica de Chile, Santiago, 2004, pp. 173-4; NovoA Monreal, Eduardo, Curso de Derecho Penal chileno, $3^{\circ}$ Edición, Edit. Jurídica de Chile, Santiago, 2005, p. 353; Garrido Montt, Mario, Derecho Penal. Parte General, (Tomos I y II), 4ª Edición, Edit. Jurídica de Chile, Santiago, 2007, p. 32.

${ }^{15}$ Maldonado Fuentes, Francisco, "Determinación de la pena y concurso de delitos en la ley 20.084", Documento de trabajo № 20/2010, Unidad de Defensa Penal Juvenil, Defensoría Penal Pública, pp. 26 y ss.

16 Por todos, Horvitz L., como en nota n, 14, p. 113. Oo., exclusivamente, en SAN MARTIN, como en nota $\mathrm{n}, 14$, p. 297.

17 Por lo dicho resulta inevitable concluir que lo que se denomina como reglas de extensión de la pena (arts. 21 a 23) no son mas que la fase propia de la determinación legal de la misma, mientras que aquellas que se agrupan en torno a la determinación de su naturaleza (arts. 23 y 24) son en concreto reglas propias de la individualización. La denominación expuesta por el legislador es por ello relativamente inexacta. 
en la ley para la sanción penal juvenil ${ }^{18} / 19$, debiendo agregar a ello que se trata de una dinámica coherente con el principio de discrecionalidad judicial que caracteriza a la fijación de la penal juvenil en torno a una mayor incidencia de la individualización judicial ${ }^{20}$.

De esta forma, es indiscutible que los criterios previstos en el art. 24 no sólo resultan aplicables en esta fase de individualización concreta de la pena juvenil, sino que resulta forzoso considerarlos en su desarrollo. Pero también es preciso considerar que técnicamente se trata de variables que no forman parte de la dinámica de valoración propia de la fase primaria de la determinación de la pena, que se confía materialmente a un conjunto de reglas centradas en la penalidad prevista en la ley penal general. Y es que conforme al contenido concreto de cada una de las etapas de la determinación de la pena, el fundamento histórico que subyace a su definición y distinción ${ }^{21}$, el producto o resultado que emana de ellas (esto es, un marco penal compuesto por sanciones de adolescentes) su fundamento y rol en la determinación de la pena y considerando concretamente el tenor literal de las disposiciones contenidas en los arts. 21 a 23, parece claro que el objeto de esta primera fase consiste en determinar un índice de aflictividad expresado en una pena de adultos. El objetivo que se persigue es que dicho rango permita determinar un abanico de sanciones propias de los adolescentes, esto es, que se transforme desde una pena de adultos a una pena de adolescentes. De ahí que en su precisión no resulten relevantes las consideraciones especiales que plantean las particularidades del menor de edad, las que recién entran en juego una vez que contamos con un marco de sanciones propias de los adolescentes. Es decir, éstas sólo cobran sentido,

\footnotetext{
18 Vid. Supra Nota $\mathrm{n}^{\circ} 5$.

19 Técnicamente el proceso de individualización se agota en la Ley 20.084 con el análisis de las normas que habilitan al sentenciador a imponer sanciones copulativas, particularmente en los casos previstos en los arts. 19 y 25. Para algunas particularidades comunes Vid. Maldonado Fuentes, como en nota $N^{\circ} 15$, pp. 21 y ss.

${ }^{20} \mathrm{Al}$ respecto Vid. Cillero Bruñol, Miguel, "Consideraciones para la aplicación del criterio de idoneidad en la determinación de las sanciones en el Derecho Penal de adolescentes chileno", Documento de Trabajo № 13, Unidad de Defensa Penal Juvenil, Defensoría Penal Pública, año 2008, p. 1; HeRnandez, Héctor, "El nuevo derecho penal de adolescentes y la necesaria revisión de su teoría del delito", Revista de Derecho de la Universidad Austral de Chile, Vol. XX. №2, , pp. 197 y 202; Maldonado Fuentes, Francisco, "La especialidad del sistema de responsabilidad penal de los adolescentes. Reflexiones acerca de la justificación de un tratamiento penal diferenciado", Justicia y Derechos del Niño $N^{\circ} 6$, 2004, pp. 122-3, del mismo, "Responsabilidad penal juvenil: estado actual y perspectivas", en http:// www.microjuris.com, año 2009. Se cita MJCH_MJD372 |MJD372, p. 3 [visitado el 16/08/2011] y en, del mismo, como en nota $N^{\circ}$ 15, pp. 12 y ss.; Medina Schulz, como en nota $^{\circ}$ 6, p. 9. Vid., asimismo, los arts. 6.1, 7.1 a) y 18.1 de las Reglas Mínimas para la Administración de la Justicia de Menores (Beijing), de 1985.

${ }^{21}$ Al respecto Vid. HL, pp. 633 y ss., especialmente 634, 637, 639; Sobre la evolución legislativa del modelo Vid. Maldonado Fuentes, como en nota №15, pp. 28 y ss.
} 
"Fundamentación y determinación de la pena en el derecho penal de adolescentes. A propósito del juicio seguido contra B. N. M. por delito de robo con intimidación (RUC 0900505404-1) en la V Región"

en cuanto criterios de determinación de pena especiales, a la hora de razonar sobre la aplicación concreta de las sanciones penales propias del régimen de adolescentes, proceso que recién se inicia en la ley a partir de los tramos (marcos penales) previstos en el art. 23.

En efecto, conforme a texto expreso la etapa de determinación legal de la pena se basa en la aplicación de reglas propias del régimen de adultos, referencia que se explica por el hecho que el legislador tomó la opción de regular la gravedad de los distintos marcos penales de adolescentes previstos (en un total de 5) acorde a las valoraciones de entidad adoptadas en la ley penal general, siendo forzoso en consecuencia prever un mecanismo de conversión que permitiera transformar un determinado rango de aflictividad (pena base) que viene descrito a partir de la pena procedente en el régimen de adultos, en una pena de adolescentes ${ }^{22}$.

Se trata de un mecanismo establecido exclusivamente a los efectos de seleccionar el marco penal aplicable a partir de los criterios de gravedad previstos en la ley penal general, mecánica fundada en la necesidad de respetar las exigencias que emanan de la proporcionalidad ${ }^{23}$. En efecto, en primer lugar se

\footnotetext{
${ }^{22}$ Conviene tener presente que el legislador hubiera podido proponer una valoración propia y particular acerca de la gravedad de cada comportamiento delictivo cuando sea cometido por un adolescente, tarea que le habría demandado la elaboración de una especie de parte especial ad-hoc que replicara cada descripción delictiva y la asociara a un respectivo y nuevo marco de sanciones posibles de imponer. Esta opción no solo parece poco práctica e innecesaria, sino además inconveniente, pues implicaría una amplia toma de decisiones legislativas respecto de la sanción de cada uno de los delitos, contraria a la necesidad de fortalecer la valoración de las particularidades del hecho en perjuicio de sus contenidos generales. La ventaja es que permite realizar una valoración concreta de cada comportamiento punible desde la perspectiva de un adolescente, cuestión que hoy en día se demanda desde la doctrina a nivel legislativo, en la interpretación de los tipos penales y en el proceso de individualización de la pena (Hernandez, como en nota n. 20, p. 201 y ss.; Maldonado Fuentes, 2009, como en nota n. 20, p. 4). La otra opción consiste en regular la existencia de unos pocos marcos penales compuestos cada uno por una amplia gama de alternativas de sanción, alternatividad que debe reflejarse tanto en lo relativo a su naturaleza como a su extensión, camino que es precisamente el seguido por nuestro legislador. A partir de esos marcos debe el legislador proponer una mecánica o fórmula para su asociación a cada uno de los delitos que generen responsabilidad conforme a la ley, existiendo para ello, también, diversas alternativas posibles de implementar, que no son sino fórmulas de conversión. Vid. HL, pp. 639 y 641.

${ }^{23} \mathrm{Al}$ respecto hay que tener presente que la asociación que supone la fijación de un marco penal da cuenta de una asignación de gravedad. No en vano -y cualquiera sea la perspectiva que se adopte al respecto- suele ser el indicativo o factor a partir del cual se emite el juicio de proporcionalidad. Sobre esta decisión se establece o fija, además, una relación que se define en términos comparativos, permitiendo situar a un determinado comportamiento punible en relación con los demás (En este sentido, por ejemplo, se centra la difundida crítica a la relación de protección que se refleja en nuestra legislación entre los valores de la vida y la propiedad, donde la gravedad de las sanciones previstas dan cuenta de una sobrevaloración de este último interés). De más está señalar que estas funciones (ambas) se ven favorecidas en su apreciación por la prioridad que el legislador concede en nuestro entorno cultural al uso de la pena privativa de libertad. Sobre esa base las ponderaciones y comparaciones relativas a la proporcionalidad suelen expresarse en dimensiones cuantitativas, y, en concreto, en extensiones o años de privación de libertad. No es por ello aventurado afirmar que los delitos se pueden pesar en un quantum de encierro, regla y perspectiva que precisamente sigue en este caso nuestro legislador.
} 
pretende conservar la debida proporción objetiva de las sanciones aplicables a cada delito conforme a su gravedad, asegurando que en el sistema juvenil, al igual que en el de adultos, los delitos más graves siempre tengan una sanción más rigurosa que los delitos menos graves ( $p$. ej. que el robo sea siempre sancionado en forma más gravosa que el hurto). A ello se orienta el que se tome como base, siempre, la pena prevista en la ley penal general para el ilícito correspondiente (art. 21 primera parte).

Luego, se pretende también conservar la debida proporcionalidad que debe existir en la sanción de un adolescente respecto de la condena que fuere aplicable a un adulto por el mismo hecho, a partir del supuesto -indiscutido- de que la condena del primero debe ser inferior a la que resultaría aplicable al segundo. Ello explica la rebaja en un grado prevista en el art. 21 (segunda parte del art. 21) y la necesidad de considerar el efecto que producen las eventuales modificaciones a la responsabilidad penal en el régimen de adultos (art. 21 tercera parte), reglas que de no ser valoradas pondrían en riesgo dicho margen proporcional. En concreto, una rebaja de pena de adultos no considerada en esta fase del procedimiento de adolescentes posibilitaría que este último reciba una consecuencia más gravosa respecto a la que resultaría aplicable al adulto conforme a las reglas generales, resultado que resulta intolerable en el sistema en atención al aludido criterio de proporcionalidad relativa.

Resumidamente, ésta, y no otra, es la función precisa que cumple el artículo 21 de la Ley 20.084, centrada en la finalidad de garantizar la proporcionalidad objetiva de los delitos y, al mismo tiempo, una base de proporcionalidad relativa respecto a la sanción aplicable conforme al régimen de adultos, bajo el entendido que el régimen de aflictividad debe ser siempre menor en caso de un adolescente ${ }^{24}$.

Con ello queda aún más claro que los criterios previstos en el art. 24 no resultan aplicables en dicha etapa pues en ella su busca determinar cuál sería la pena aplicable al adulto por los mismos hechos, conclusión que, por lo demás, se confirma en el texto expreso de las disposiciones en juego. En efecto, los criterios que deben ser valorados en las diversas instancias donde opera la discrecionalidad judicial en la aplicación de las reglas que dispone considerar el art. 21 son diversos a los mencionados especialmente en la Ley 20.084, centrándose en general en factores como el número y la entidad o gravedad de las circunstancias concurrentes (en particular los arts. 65 a 68 bis. del CP) $)^{25}$.

\footnotetext{
${ }^{24}$ Comparten por ello el mismo fundamento con el art. 26 inc. 2, que dispone que "en ningún caso se podrá imponer una pena privativa de libertad si un adulto condenado por el mismo hecho no debiere cumplir una sanción de dicha naturaleza".

25 Vid. por todos Cury URzúa, como en nota n. 14, p. 768.
} 
"Fundamentación y determinación de la pena en el derecho penal de adolescentes. A propósito del juicio seguido contra B. N. M. por delito de robo con intimidación (RUC 0900505404-1) en la V Región"

\section{Valoración del fallo}

Lo dicho parecería servir de base para rechazar la causal de nulidad propuesta por la recurrente, a saber, el que en este caso el Tribunal de instancia haya incurrido en una falta de fundamentación, precisamente por no considerar en su razonamiento algunos de los criterios previstos en el art. 24 y en el 26. No obstante, y muy lejos de ello, es posible constatar (y así lo anticipamos) que a la hora de resolver la pena concreta aplicable (esto es, a la hora de proceder a la individualización de la sanción), el Tribunal se conforma con indicar que la pena se impondrá en el mínimo previsto, sin exponer razonamiento alguno que justifique dicha conclusión. Si bien en una perspectiva orientada por la mínima intervención -como la que se extrae de lo resuelto, toda vez que aplica el mínimo de pena posible de imponer-dicha conclusión debiera ser considerada adecuada, hemos ya visto que el vicio invocado apunta exclusivamente a la exigencia de un razonamiento y su formalización, cuestión que, con independencia de los resultados, detenta un valor constitucional propio, digno de tutela y protección, a cuyo tratamiento se dirige la causal de nulidad aludida ${ }^{26}$. La cuestión es, por ello, que en este caso la sentencia no puede dar cuenta de que han sido considerados todos los criterios que el legislador ha previsto para la fijación de la pena, ni puede por ello sostener que se trata de una conclusión discrecional, ajustada a la legalidad, mostrándose más cercana a una decisión motivada por criterios personales del redactor.

Sin embargo las reflexiones que amerita este proceso no se limitan a esta constatación. Y es que resulta igualmente relevante destacar que la propia recurrente yerra a la hora de exigir la aplicación de los criterios previstos en el art. 24 de la Ley 20.084 en la denominada fase primaria de la determinación de la pena, error en que, por lo demás, también incurre el propio Tribunal, al sustentar el uso de la facultad de aumento de grado prevista en el art. 67 del CP (aplicable a partir del art. 21 de la Ley 20.084) en motivos como la "real y efectiva resocialización" o la necesidad de "fortalecer [ ] el respeto del adolescente por los derechos y libertades de las personas y sus necesidades de desarrollo e integración social", criterios orientativos que se extraen de las mismas reglas contenidas en el art. 24. Yerra por ello en cuanto se trata de orientaciones aplicables al proceso de individualización (consignadas particularmente en torno al criterio de idoneidad previsto en el art. 24 letra f) de la Ley 20.084) y que resultan irrelevantes en la aplicación del inciso quinto del art. 67 en la fase de determinación legal de la pena, disposición que cuenta con parámetros propios para el uso de las facultades discrecionales que regula. Dichos parámetros co-

${ }^{26}$ Sin ánimo de entrar en el análisis de fondo, quisiéramos a este respecto recordar la estrecha asociación que existe entre este requisito y la satisfacción de las exigencias que impone el principio de legalidad. 
rresponden, en concreto, al número y entidad de las circunstancias concurrentes, establecidos a nivel general en las disposiciones que regulan el efectos de las circunstancias modificatorias de la responsabilidad penal en la determinación de la pena (arts. 65 a 68 bis del CP), como en el propio art. $67^{27}$.

De ahí que, en primer lugar, sea erróneo que el sentenciador de la instancia haya considerado parámetros diversos en este caso y no los que, conforme a la ley, debieran haber orientado su razonamiento en particular. Pero también, y en segundo lugar, constituye un vicio de la misma entidad el que paralelamente no haya dado cuenta de la totalidad de dichos criterios, esto es, del conjunto de aquellos que sí debía considerar.

En efecto basta ver el texto para apreciar que no se expone ningún desarrollo en torno al por qué el número de circunstancias que da por acreditadas (reincidencia y pluralidad de malhechores) debe traducirse en un aumento de la penalidad, ni se refiere al contenido ni a la entidad (es decir, a la gravedad) precisa de la agravante de pluralidad de malhechores. Se limita por ello a desarrollar solo uno de los razonamientos que resultan exigibles, argumentando en torno al sentido agravatorio que puede atribuirse a la reincidencia. Postula, en concreto, que la imposición de una condena precedente, seguida de la reiteración, revela su insuficiencia "lo que determina, a juicio del Tribunal, que deba ahora ser objeto de una medida de intervención mayor, a fin de lograr una real y efectiva resocialización no lograda antes" ${ }^{28}$.

Con independencia del fondo (cuestión que no atañe al problema que ahora nos ocupa), lo relevante es que al argumentar en forma aislada sobre la base de uno solo de los motivos exigibles en el sentido indicado, el Tribunal le está atribuyendo a su sola consideración la propiedad de generar el aumento de penalidad regulado, efecto que no resulta posible de conciliar con el texto legal,

\footnotetext{
${ }^{27}$ Más de alguien podría rechazar la aplicación de dichos criterios en atención a que no se mencionan en forma expresa en el inciso quinto del art. 67 aludido en el texto. Al respecto hay que considerar que si bien es efectivo que dicha mención no se incluye en forma expresa en el apartado citado, se trata de factores mencionados precisamente en el inciso precedente de la misma disposición, donde se regula una facultad similar, esta vez, aplicada al caso de rebajas de penalidad, siendo lógico concluir, en una lectura continua, que han sido considerados en dicho lugar con una vocación de aplicación general respecto a todo el cuerpo del artículo. Pero además se trata de los criterios que el legislador menciona en todas las disposiciones del CP donde regula la posibilidad de que el juez resuelva discrecionalmente aumentos o rebajas de grado en atención a la concurrencia de circunstancias modificatorias de responsabilidad penal (arts. 65 a 68). Por lo demás hemos visto que resulta forzoso que el legislador haya previsto factores concretos que orienten la actuación judicial en dichos casos, pues, de lo contrario, la facultad judicial que concede sería difícilmente conciliable con las exigencias del principio de legalidad. La pena sería, en dichas aplicaciones, ajena a las valoraciones legales, y difícilmente calificable como discrecional, en cuanto cercana más bien a la arbitrariedad. De ahí que de no considerarse aplicables dichos criterios el tribunal debiese más bien prescindir del uso de dicha facultad, a riesgo de contaminar la resolución con algún vicio, por defectos presentes en la propia ley.

${ }^{28}$ Considerando Decimosexto.
} 
"Fundamentación y determinación de la pena en el derecho penal de adolescentes. A propósito del juicio seguido contra B. N. M. por delito de robo con intimidación (RUC 0900505404-1) en la V Región"

que exige al menos dos razones (circunstancias) y de entidad, para ello. Queda en evidencia en el contenido de la argumentación sostenida en la sentencia toda vez que el razonamiento expuesto precisamente le atribuye dicha propiedad agravatoria al sólo hecho de la reincidencia, siendo en paralelo evidente que la concurrencia (y por ello el razonamiento acerca) de dos agravantes constituye el presupuesto básico que permite el juez hacer uso de la facultad de aumento de grado.

Hay que tener además presente que dicha la concurrencia de las agravantes no es un antecedente que el legislador considere suficiente para detonar dicho aumento, siendo sólo un supuesto que le hace arbitrar dicho efecto como una posibilidad ${ }^{29}$. Habrá entonces, conforme a ello, determinados casos en que dicho número permitirá el aumento y otros en que será necesario una concurrencia mayor de motivos de agravamiento de pena, como también podrían existir casos en los que dicho número, o uno superior, no parezca suficiente para generarlo.

Si bien es evidente que ello dependerá a fin de cuentas de la entidad, gravedad y contenido de las circunstancias que en los hechos concurran, es la propia ley la que obliga además a considerar su número o cuantía como criterio independiente. Por ello de lo que se trata es de una exigencia mayor de fundamentación en aquellos casos en que sea baja la cantidad de circunstancias y a pesar de ello se pretenda elevar la pena, como también deberá elevarse dicho estándar si es mayor la cantidad de circunstancias y no se estima procedente el aumento.

$\mathrm{Al}$ respecto hay que tener presente que en este caso en particular se hace aún más necesario un buen desarrollo de la entidad o mayor gravedad de las circunstancias que se estiman concurrentes, pues, como veremos más adelante, se trata de dos supuestos agravatorios (reincidencia y pluralidad de malhechores) cuya inherencia en el delito cometido por un adolescente se discute, lo que anularía su consideración autónoma ${ }^{30}$.

A pesar de todo lo señalado, es Ilamativo que la Corte de Apelaciones de Valparaíso haya considerado, en sus dos pronunciamientos, que la sentencia del Tribunal de instancia había cumplido con las exigencias legales de fundamentación. El error en este caso consiste en que para ello se consideran razonamientos que expone el Tribunal y que no tienen vinculación alguna con los parámetros

29 Vid. por todos Cury URZúA, como en nota n. 14, p. 769.

30 Vid. Al respecto Carneval, Raúl; Källman, Eva, "La importancia de los grupos en el comportamiento juvenil. Especial consideración a la pluralidad de malhechores del artículo 456 bis nº3 del Código Penal", En: http://www.políticacriminal.cl N4, 2007, pp. 17 y 18 [visitado el 16/08/2011]; CousO SALAS, Jaime, "Notas para un estudio sobre la especialidad del derecho penal y procesal penal de adolescentes: El caso de la Ley chilena", Justicia y Derechos del Niño N 10, 2008, pp. 107-8; MaLdonado Fuentes, 2009, como en nota $N^{\circ} 20$, p. 9. 
legales de individualización que deben ser considerados. Incluso más, ni siquiera tienen que ver con el ámbito de la determinación de la pena. Por ejemplo, la sala que conoció de la segunda vista del recurso entendió que el hecho que los sentenciadores se [hayan hecho] cargo de toda la prueba rendida en el juicio tanto para determinar el hecho punible cuanto para establecer la participación de los condenados" ${ }^{\prime 31}$ es lo que permite afirmar que no se ha incurrido en el vicio reclamado, a pesar que la valoración de la prueba es un ámbito normativo completamente diverso y ajeno a la individualización de la pena ${ }^{32} / 33$.

Por su parte la primera resolución de nulidad sostiene que la fundamentación que permitiría apreciar que los jueces reflexionaron sobre el fondo y forma de la cuestión debatida estaría en el párrafo décimo de la sentencia, lugar en el que, lejos de ello, el Tribunal reflexiona exclusivamente acerca de la procedencia de la agravante de pluralidad de malhechores. Es decir, no razona sobre el efecto de su concurrencia en la determinación de la pena, sino en torno a si se trata de una circunstancia que deba ser considerada en dicha instancia ${ }^{34}$.

A este respecto hay que tener presente que el análisis acerca de la concurrencia o procedencia de las circunstancias modificatorias de la responsabilidad penal y la valoración de los efectos que acarrea su consideración para la determinación de la pena son dos cosas muy diversas. La primera dice relación con cuestiones de hecho y de valoración jurídica relativas a su aplicabilidad, y concluye con una resolución acerca de si dicha circunstancia debe formar parte del supuesto fáctico que deberá ser valorado a la hora de precisar las consecuencias. La segunda es una dinámica que opera en un momento posterior, una vez que ha concluido el análisis de todo el contexto fáctico y de el propio

\footnotetext{
31 Considerando Cuarto.

32 Lo dicho se confirma en el Considerando Quinto, donde la Corte señala que: "para apreciar la prueba les ha puesto la limitación consistente en que no pueden contradecir los principios de la lógica, las máximas de la experiencia y los conocimientos científicamente afianzados, cuya trasgresión no se aprecia en el fallo recurrido; por otra parte, la defensa del condenado Núñez, no refiere de qué manera los sentenciadores habrían vulnerado las mencionadas limitaciones".

${ }^{33}$ No podemos dejar de mencionar que la Corte (en su primera resolución), en este caso en particular, también incurre en el error de considerar que la fundamentación expuesta en el Considerando Decimosexto de la sentencia de instancia (esto es, aquél que le permite al tribunal aumentar el grado, a partir de una insuficiente argumentación de los parámetros exigibles para la aplicación del inciso quinto del art. 67 del CP y a partir de criterios propios del art. 24 de la Ley 20.084 que no son procedentes de considerar) constituye una argumentación que satisface lo exigible a este respecto (Considerando cuarto).

${ }^{34}$ Además de ello la Corte estima que los sentenciadores "también aludieron al segmento etario que involucra al acusado en cuanto a adolescente" entendiendo que se trata de algo que forma parte de la argumentación o fundamentación de la individualización de la pena. Según ya hemos visto no se trata de un criterio a ser considerado en dicha instancia (ni en la determinación legal ni en la individualización). A lo sumo, puede ser apreciado como una consideración que opera como supuesto que hace operativa la ley y del cual emanan criterios diferenciales.
} 
"Fundamentación y determinación de la pena en el derecho penal de adolescentes. A propósito del juicio seguido contra B. N. M. por delito de robo con intimidación (RUC 0900505404-1) en la V Región"

de los presupuestos que debieran ser ponderados a la hora de determinar la pena, acotando su objeto a esta última tarea. En este último caso la valoración jurídica que se demanda al juez se vincula precisamente a dichos efectos, es decir, a la incidencia que tiene su concurrencia en la pena que se debe imponer, análisis que debe realizarse en un proceso único y ponderativo de la totalidad de las características generales y particulares que concurren en la comisión del delito. Volveremos sobre esta cuestión más adelante.

Conviene finalmente apuntar que también la Corte de Apelaciones parece incurrir en el vicio a la hora de plantear la sentencia de reemplazo. Si bien la ausencia de modificatorias le permite obviar la necesidad de fundamentar en la etapa de determinación legal de la pena (en dicho supuesto ya tiene determinado el grado de pena que le permitirá realizar la conversión en el art. 23) es indiscutible que se encuentra obligado a hacerse cargo de los criterios de individualización previstos en el art. 24 a la hora de escoger la sanción concreta a imponer. Sin embargo, en lugar de ello procede a justificar la sanción (de tres años y un día de internación en régimen cerrado), en base a que se estima una pena más proporcionada con el delito y sus circunstancias", parámetros más próximos, pero no exactos, a los previstos en el régimen general de adultos, que ni siquiera se da el trabajo de desarrollar. No hay que olvidar además que en el tramo respectivo el Tribunal debe optar entre internación en régimen cerrado, internación en régimen semicerrado o la libertad asistida especial, con una duración que en los dos primeros casos puede ir entre los tres años y un día a los cinco años, y alcanzar, en el último caso, los tres años de duración, sin que haya procedido en modo alguno a precisar las razones que le llevan a escoger la sanción más gravosa en cuanto a la naturaleza con la duración más favorable. Llama asimismo la atención que el nivel de compenetración con la especialidad del sistema que demuestran los sentenciadores de este fallo a la hora de precisar los motivos que les llevan a excluir de toda consideración a las agravantes de pluralidad de malhechores y de reincidencia parecen desaparecer (y por completo) cuando se enfrentan a la tarea de determinar la pena, siendo tan relevantes en uno como en otro caso $^{35}$.

III. Pluralidad de malhechores y reiteración delictiva en la ley No 20.084: ANÁlisis MATERIAL DE LA REMISIÓN AL CP QUE CONTIENE EL ART. $1^{\circ}$ INC. $2^{\circ}$ DE DICHO CUERPO NORMATIVO

Como segunda cuestión a analizar nos concentraremos en la argumentación expuesta en las diversas resoluciones en torno a si procede considerar en los delitos cometidos por adolescentes las agravantes conocidas como pluralidad

35 Lo más llamativo es que recurren a dichos contenidos materiales en aquél ámbito donde aún se discute su procedencia, sin darle aplicación donde parece ser más usual considerarlos. 
de malhechores, prevista en el numeral 3 del art. 456 bis, y la de reincidencia, contenida en el art. $12 \mathrm{~N}^{\circ} 16$, ambos del CP. El debate se suscita por cuanto la recurrente sostuvo en el juicio que resultaba improcedente considerar la primera de ellas (pluralidad de malhechores) a partir de un razonamiento de carácter material, centrado en una caracterización del comportamiento adolescente que permite sostener que en dicha etapa resulta natural o consustancial el proceder a actuar en la vida cotidiana en grupos ${ }^{36}$. De esta forma, la sola constatación de que el infractor pertenece a dicho tramo etario llevaría implícita dicha forma de comportamiento, resultando por ello una modalidad inherente a la propia ejecución del delito. Su consideración autónoma, como elemento de juicio ajeno y adicional a la intervención delictiva, conllevaría por ello una especie de sanción o agravación de pena en base a la concurrencia de un elemento de juicio del que el adolescente no puede prescindir o, mejor dicho, cuya prescindencia no resultaría exigible ${ }^{37}$.

Por su parte es la Corte de Apelaciones la que, resolviendo el recurso de nulidad deducido, se inclina por declarar improcedente la agravante de reincidencia sobre una base o fundamento de similares características. Si bien reconoce expresamente que "la conducta del joven es reprochable" en alusión al hecho mismo de la reiteración, considera que este reproche (generado en la recaída) "no tiene el mismo sentido y profundidad que [aquél] que se le puede atribuir a un adulto", pues las particulares características del adolescente no permitirían afirmar que detenta la misma "noción del reproche social". Considera asimismo, coherentemente, que la reincidencia ha sido regulada en la ley penal general tomando como base el comportamiento de un adulto "sabedor, se supone, del concepto del bien y el mal, a lo menos en su esencialidad", en razón a lo cual no puede resultar de aplicación automática frente a los adolescentes ${ }^{38}$.

Ahora bien, la solicitud relativa a la inaplicabilidad de la pluralidad de malhechores es directa y expresamente desechada por el Tribunal de instancia. Recurriendo a una lectura literal de la Ley 20.084 rechaza sintéticamente dicha argumentación basándose exclusivamente en un razonamiento formal: el hecho que dicha circunstancia no resulta expresamente (positivamente) excluida en el texto normativo. Para ello asume como presupuesto que en aquellos casos en que la Ley 20.084 "ha querido excluir la aplicación de alguna disposición o principio a aquellos menores, lo ha señalado en forma expresa." Este apego a la literalidad hace que el Tribunal incluso rechace el entrar a analizar si la

\footnotetext{
36 Vid. Carnevali; Kallman, como en nota n. 30, pp. 17 y 18.

37 HeRnANDEZ (como en nota n. 20, pp. 214 y 215) expone con bastante claridad la necesidad de enfrentar el análisis de las circunstancias modificatorias de responsabilidad en estos casos a partir de una mecánica análoga a la utilizada por el Tribunal.

${ }^{38}$ Considerando Sexto (en relación al fundamento expuesto en el Considerando Quinto).
} 
"Fundamentación y determinación de la pena en el derecho penal de adolescentes. A propósito del juicio seguido contra B. N. M. por delito de robo con intimidación (RUC 0900505404-1) en la V Región"

argumentación de la defensa es sustentable por razones materiales ${ }^{39}$. Atendido su contenido, es presumible que dicha argumentación se hubiere replicado en plenitud respecto de la agravante reincidencia, en caso que la defensa hubiere expuesto un desarrollo crítico similar al que desarrolla la Corte de Apelaciones a este respecto, en tanto se trata de una circunstancia que tampoco aparece formalmente excluida en el texto de la Ley 20.084. Lo confirma el que, sin más trámite, ni desarrollo, el Tribunal de instancia procede a considerar concurrente dicho motivo de agravación en base a que B. N. había sido anteriormente condenado por otro delito de robo con intimidación (agregando) "único hecho que debe considerarse para la aplicación de la agravante".

Lo central es que este proceder del Tribunal no parece tolerable en atención a dos órdenes de consideraciones. Primero, pues entendemos que debió haberse hecho cargo del plano material en el que se materializa la petición de la defensa, esto es, que debió proceder a razonar sobre el fondo de la cuestión invocada. No se trata de que el argumento formal no sea relevante e incluso que no pueda llegar a ser determinante. La cuestión es que el hacerse cargo solo de dicho plano habiéndose planteado un debate de fondo ${ }^{40}$, deja siempre abierta una duda acerca de la razonabilidad de fondo de las pretensiones deducidas, inquietud que inevitablemente se extiende, por ese solo hecho, al propio texto normativo.

En segundo lugar, y en cuanto al fondo, resulta bastante discutible que el sistema previsto en la Ley 20.084 contenga efectivamente una reglamentación fragmentaria que se encuentre montada, y por ello dependa, de todas y cada una de las reglas previstas en el régimen penal general. De ser así, la responsabilidad penal adolescente sería una forma más de hacer efectiva la responsabilidad penal general que sólo gozaría de modificaciones puntuales y específicas acordadas en atención a la condición etaria y personal del infractor. Sería una especie de caso especial o excepcional que compartiría una naturaleza común y única con las bases de la responsabilidad penal general.

Dicha forma de entender el modelo es propia de los sistemas más clásicos de responsabilidad penal de menores de edad, que consideran que las cuestiones atinentes a la minoridad se motivan exclusivamente en razones de culpabilidad, y que llevan a radicar todo el contenido de la especialidad del modelo en la

\footnotetext{
${ }^{39}$ Señala: "Tampoco reviste análisis la alegación en el sentido que <es consustancial a los adolescentes el actuar en grupos $>$, pues ninguna exclusión a este respecto se observa en la ley de responsabilidad adolescente". El lenguaje es Ilamativo pues la Corte sustenta directamente que se trata de un punto que no amerita análisis, confirmando lo que hemos sostenido en el texto.

${ }^{40}$ Ello no resultaría exigible en relación a la reincidencia, precisamente porque se trata de un debate que no ha sido motivado por la defensa.
} 
óptica de la semiimputabilidad ${ }^{41}$. Esta concepción, por ejemplo, se encontró históricamente vigente en nuestro ordenamiento hasta que fuere derogada por la Ley 20.084, concretamente consagrada en el sistema previsto para el tratamiento penal de los menores de entre 16 y 18 años respecto de los cuales se hubiere declarado que al cometer un delito obraron con discernimiento ${ }^{42}$. A su respecto se consideraba una base de responsabilidad centrada tanto en los delitos como en las sanciones previstas en general en el CP, radicando la diferencia exclusivamente en la consideración de una rebaja en la penalidad, atenuación cuyo fundamento siempre fue interpretado como propio de una menor reprochabilidad por razones de imputabilidad, esto es, una condición que es propia del ámbito de la anormalidad ${ }^{43}$.

Nada de ello se puede sostener en el modelo instaurado en la Ley 20.084. Primero, en atención a que en la historia de su gestación se fundamenta la necesidad de una reforma precisamente en lo inevitable que resulta superar los sistemas propuestos bajo los modelos tradicionales (clásico y tutelar), radicando el nuevo modelo en torno al denominado sistema de responsabilidad especial ${ }^{44}$. En dicho contexto se trata de un modelo configurado íntegramente en función

\footnotetext{
41 Al respecto Maldonado Fuentes, 2009, como en nota n. 20, pp. 3 y ss.

42 Al respecto Cillero Bruñol, Miguel, "Comentario al artículo 10 № 2 y 3", en Politoff; Ortiz (Dir.) Matus (Coord.), Texto y Comentarios del Código Penal Chileno, Tomo I, Libro Primero, Parte General, Edit. Jurídica de Chile, 2002, pp. 115 y ss.

${ }^{43}$ Al respecto Vid. Maldonado Fuentes, 2009, como en nota n. 20, p. 3

${ }^{44}$ Se puede apreciar nítidamente en el mensaje con que el Presidente de la República inicia el trámite de esta nueva normativa (Vid. HL pp. 7 y ss.); Sobre el fondo Vid. HeRnándeZ, como en nota n. 20, pp. 196 y ss; Maldonado Fuentes, 2004, como en nota n. 20, pp. 115 y ss. Las bases de este sistema se consagran en un conjunto de instrumentos internacionales que sirven de fuente directa. La fuente principal se ubica en los artículos 37 y 40.3 de la Convención Internacional sobre Derechos del Niño (1989). Sin embargo debe además considerarse el contenido de las Reglas mínimas para la administración de la justicia de menores (Beijing) (1985); de las Reglas mínimas para la protección de menores privados de libertad (1990) y de las Directrices de Naciones Unidas para la prevención de la delincuencia juvenil (RIAD) (1990). No está de más recordar que todos estos instrumentos (individualmente considerados) conforman un estatuto o corpus que pasa a integrar el contenido del artículo 19 de la Convención Interamericana de Derechos Humanos (Pacto de san José de Costa Rica) conforme al criterio sostenido por la Corte Interamericana de Derechos Humanos en los fallos Villagrán Morales, conocido como $<$ niños de la calle > (Guatemala), 1999; Walter Bulacio (Argentina) e "Instituto de Reeducación Superior $<$ Panchito López>" (Paraguay), y en la Opinión Consultiva N 17 de la Corte Interamericana: "Condición Jurídica y Derechos Humanos del Niño" (2002), instrumento interpretativo de validez general. Bajo estas premisas la competencia de los órganos del pacto no parece discutirse, como tampoco la recepción interna en nuestro derecho positivo en base a lo dispuesto en el inciso segundo del artículo 1 de la Ley 20.084 ("En la aplicación de la presente ley, las autoridades tendrán en consideración todos los derechos y garantías que les son reconocidos en la Constitución, en las leyes, en la Convención sobre los Derechos del Niño y en los demás instrumentos internacionales ratificados por Chile que se encuentren vigentes"). Vid., asimismo, DuCE Julı, Mauricio, "El derecho a un Juzgamiento especializado de los jóvenes infractores en el Derecho Internacional de los Derechos Humanos y su impacto en el diseño del proceso penal juvenil", lus et Praxis Año 15, № 1, 2009, pp. 77 y ss.
} 
"Fundamentación y determinación de la pena en el derecho penal de adolescentes. A propósito del juicio seguido contra B. N. M. por delito de robo con intimidación (RUC 0900505404-1) en la V Región"

al comportamiento adolescente generando una responsabilidad que, si bien es de carácter penal, resulta definida en base a condiciones, objetivos y finalidades diversos a los previstos en el régimen general de adultos. De ahí que el propio art. $10 \mathrm{~N}^{\circ} 2$ del CP excluya por principio su propia aplicación para los delitos cometidos por personas menores de 18 años $^{45}$. Con ello la regla de base es que la responsabilidad penal de adolescentes se radica directamente en un modelo especial, previsto en un cuerpo normativo diverso, sin que puedan interpretarse por ello los contenidos de la Ley 20.084 como meros fragmentos modificatorios aplicables sobre el sistema general previsto en el CP.

Queda en evidencia si se atiende a las consecuencias previstas en este modelo especial, elemento que constituye un indicativo relevante a la hora de definir los caracteres de la responsabilidad. Lo importante es que las sanciones previstas como consecuencia de la responsabilidad penal de adolescentes son esencialmente diversas a las previstas en el régimen penal general ${ }^{46}$, mostrando distintivos no sólo en el plano cuantitativo, sino también en el cualitativo ${ }^{47}$. La idea de base es por ello que el adolescente responde en forma diversa, principio que afecta a todo el sistema que regula su responsabilidad. De ahí que no sólo se trate de una característica aplicable al contenido de las sanciones, extendiéndose cuando menos al sistema previsto para su determinación (tendencialmente proclive a una mayor discrecionalidad ${ }^{48}$ y al sistema dispuesto para su revisión o modificación en sede de ejecución y que, según veremos, también se replica en los demás presupuestos operativos del modelo, abarcando incluso a las definiciones propias de lo injusto ${ }^{49}$.

Todos estos institutos se configuran de forma diversa en atención a que el adolescente presenta particularidades constitutivas que lo hacen reaccionar de manera distinta frente al contenido normativo que propone el sistema penal,

45 "Están exentos de responsabilidad criminal (...) N²: El menor de dieciocho años. La responsabilidad de los menores de dieciocho años y mayores de catorce se regulará por lo dispuesto en la ley de responsabilidad penal juvenil".

46 Reconocemos que la caracterización que hoy en día presentan en la práctica buena parte de las sanciones previstas en la Ley 20.084 (especialmente las privativas de libertad) presentan múltiples elementos que permiten asemejarlas con las penas que se administran en el sistema de adultos. No obstante se trata de un déficit que proviene de su inadecuada implementación, sin afectar por ello a la conceptualización que se desprende del texto que las establece en el nivel normativo. Se trata de un modelo en ejecución que por este solo hecho es calificable como deficitario, radicando la responsabilidad que de ello se deriva en la administración.

47 Vid. al respecto el contenido de los arts. 6 y 8 al 18 de la Ley 20.084.

${ }^{48}$ Vid. Supra Nota n. 15.

49 En este sentido Couso Salas, como en nota n. 30, pp. 105 y ss; HeRnandez, como en nota n. 20, pp. 202 y ss; Maldonado Fuentes, 2009, como en nota n. 20, pp. 9 y ss. Oo. Vargas Pinto, Tatiana: "La determinación judicial de la pena juvenil", Revista de Derecho de la Pontificia Universidad Católica de Valparaíso XXXIV, 1 semestre, p. 477. 
caracteres que llevan a configurar las finalidades de la intervención penal sobre adolescentes en forma completamente diferente respecto al régimen de adultos. Por ello no se trata sólo de que le resulta menos exigible adecuar su comportamiento a la norma, sino de reconocer que la propia lectura de contenidos que éstos realizan se desarrolla en forma diversa, precisamente en atención a particularidades que los diferencian de los adultos y que son propias de la etapa de vida en que se encuentran. Por lo mismo la lectura del delito y de la pena que el adolescente realiza es diferente, lo que se grafica tradicionalmente en el diverso significado que detenta para el adolescente y para adulto un mismo número determinado de años de encierro. En dicho periodo (2 o 3 años de encierro) es considerablemente superior lo que deja de recibir el adolescente en términos de sociabilidad respecto de la privación que representa ese mismo número de años de encierro para un adulto, con consecuencias preventivas de largo plazo evidentemente más negativas.

Sobre esas bases no parece posible sostener que la regla de subsidiariedad prevista en el art. 1 de la Ley 20.084 que se remite, en lo no reglado, al CP de adultos, deba ser entendida como una remisión ciega y automática, sino una que deba ser compatibilizada con los caracteres propios de la adolescencia, esto es, que debe realizarse previa lectura de la compatibilidad de las reglas respectivas con los caracteres básicos del modelo ${ }^{50}$, incorporados a través de los arts. 2, 20, 29 inc. 1, 44, 47 de la Ley 20.084 y 10 №2 del Código Penal ${ }^{51}$. Queda en evidencia en aquellos casos en que la minoridad expresamente es un obstáculo a la configuración de alguno de los elementos explícitos del delito (p. ej. en los delitos funcionarios) o en aquellos casos en que implícitamente las propias definiciones del legislador impiden configurar la intervención punible del infractor adolescente, en atención a que se basan en la falta de capacidad de comprensión de su significado de injusto (p. ej. en los delitos de corrupción de menores $)^{52}$. Un claro ejemplo de ello es el diverso significado que tiene la relación sexual consentida punible si interviene un menor de edad, para lo cual el propio legislador dispuso de una regla especial (art. 4 de la Ley 20.084) ${ }^{53}$. Lo

\footnotetext{
${ }^{50}$ Se trata, en términos de HeRNÁNDEZ (como en nota $N^{\circ} 22$, p.198), de una tarea forzosa para el intérprete (y, consecuentemente, para el aplicador del derecho),

51 También se aprecia en el contenido de los arts. 6, 18, 24, 26, 38, 40, 53 y 55; y en el propio texto del mensaje con el que el Presidente de la República plantea la iniciativa (Vid. HL, pp. 7 y ss.).

${ }^{52}$ Así por ejemplo, si la esencia de la punibilidad consiste en estos casos en que los menores de edad puede ver afectada su indemnidad sexual en atención a que su madurez no le permite comprender el significado de los comportamientos que se sancionan es ilógico y contradictorio suponer (pretender) que si comprenden dicho significado a la hora de intervenir como agente activo. En este sentido HeRNÁNDEZ, como en nota $N^{\circ} 22$, pp. 202 y ss.

53 "Artículo 4o.-- Regla especial para delitos sexuales. No podrá procederse penalmente respecto de los delitos previstos en los artículos 362, 365, 366 bis y 366 quater del Código Penal, cuando la conducta
} 
"Fundamentación y determinación de la pena en el derecho penal de adolescentes. A propósito del juicio seguido contra B. N. M. por delito de robo con intimidación (RUC 0900505404-1) en la V Región"

mismo se replica en la modificación introducida por la Ley 50.519 (de 21 de junio de 2011) a la Ley 18.314 y que excluye de los efectos propios del régimen antiterrorista a la responsabilidad penal que recae en los menores de edad ${ }^{54}$. Deberá por ello realizarse una revisión en cada caso acerca de si efectivamente se trata de un supuesto previsto en la reglamentación común que sea replicable en el modelo de adolescentes.

Por lo dicho entendemos que a este respecto razona adecuadamente la sentencia de nulidad en cuanto procede a contextualizar el análisis. Afirma "que los adolescentes conforman un estamento (sic) etario, que tiene sus particulares características, propias de una etapa de desarrollo previa a la adultez, con afectividades ausentes o que no los satisfacen o una marcada susceptibilidad. En su conflictivo desarrollo se unen a otras personas en busca de reconocimiento y legitimación. En esa búsqueda rompen reglas de conductas, asumiendo conductas rebeldes. El adolescente, como hombre incipiente, su madurez e intelectualidad, también lo es, y muchas veces con escasa noción del reproche social [ ]. El juez al analizar la norma y ponderar la prueba, no puede prescindir de estos criterios y aplicarlos, si es necesario, al caso concreto que conoce. En la especie en un hecho indiscutido que el acusado es un adolescente" ${ }^{\prime \prime 5}$.

A partir de ello la Corte concluye (en lo que ahora nos interesa) que "los juzgadores no consideraron que es propio de los adolescentes desarrollar su cotidianeidad junto a otro u otros sujetos. En lo que aquí interesa no hay evidencias que señalen que el muchacho buscó la compañía de otro para obtener ventajas sobre la víctima y lograr su propósito que no era otro que apropiarse de cosa mueble ajena sin la voluntad de su dueño" ${ }^{\prime \prime 56}$, desarrollando una argumentación equivalente respecto de la reincidencia, según ya hemos apuntado.

La conclusión en este caso le lleva a entender que no deben considerarse concurrentes dichas circunstancias en el presupuesto a partir del cual se deberán resolver los efectos de la responsabilidad. Se trata de una temática que se inserta en la determinación del contexto que será enjuiciado, proceso que no se agota

se hubiere realizado con una persona menor de 14 años y no concurra ninguna de las circunstancias enumeradas en los artículos 361 ó 363 de dicho Código, según sea el caso, a menos que exista entre aquélla y el imputado una diferencia de, a lo menos, dos años de edad, tratándose de la conducta descrita en el artículo 362, o de tres años en los demás casos".

54 "Artículo $1^{\circ}$.- Agréganse al artículo $1^{\circ}$ de la Ley $N^{\circ}$ 18.314, que determina las conductas terroristas y fija su penalidad, los siguientes incisos segundo y tercero, nuevos: "La presente ley no se aplicará a las conductas ejecutadas por personas menores de 18 años. (...) La exclusión contenida en el inciso anterior no será aplicable a los mayores de edad que sean autores, cómplices o encubridores del mismo hecho punible. En dicho caso la determinación de la pena se realizará en relación al delito cometido de conformidad a esta ley.". El subrayado es nuestro.

55 Considerando Quinto. El subrayado es nuestro.

56 Considerando Sexto. 
con la definición de los hechos que se estiman probados. Y es que además de ello el Tribunal al sentenciar debe realizar un análisis acerca del significado jurídico concreto que dicho contexto fáctico detenta en torno a la responsabilidad precisa de cada infractor, tarea que demarcará los presupuestos específicos sobre los cuales habrán de regularse los efectos de su responsabilidad. Se trata de saber cuál o cuáles de los aspectos propios del contexto fáctico acreditado son posibles de atribuir al infractor, conforme al contenido y sentido de la reglamentación vigente y sus caracteres particulares. Así sucede, por ejemplo, en aquellos casos en que una determinada lesión física es excluida de consideración por concurrir una justificante (cualquiera de ellas) o cuando se considera que este mismo comportamiento es socialmente adecuado (la lesión corporal provocada por el médico que realiza una intervención quirúrgica), o cuando se reduce el marco de la tipicidad formal por razones atingentes al bien jurídico protegido o por motivos referidos a la imputación subjetiva (p. ej., al exigir al menos la concurrencia de la culpa en un delito que formalmente es descrito como hipótesis calificada por el resultado) o, finalmente, cuando se suprime la consideración de cualificantes personales respecto del extraneus en los delitos especiales impropios. En todos esos casos parece claro que la dimensión fáctica no es suficiente para precisar los presupuestos que servirán de base para regular los efectos de la responsabilidad penal, siendo precisamente en dicha etapa donde se desarrolla el análisis que ahora nos ocupa y que, como ya anticipamos, se ubica en un momento previo al proceso de determinación de la pena.

Este razonamiento se confirma implícitamente en la estructura de desarrollo que propone la propia sentencia recurrida. Basta ver cómo el sentenciador se hace en ella cargo de la dimensión propiamente fáctica en primer lugar (Considerandos Sexto y Séptimo), para solo después proceder a analizar sus implicancias jurídicas (Considerandos Séptimo y Octavo), incluyendo en este lugar la revisión de la procedencia o improcedencia jurídica de las circunstancias (Considerandos Noveno, Décimo, Decimocuarto, etc.) enfrentando solo después el análisis de las consecuencias que todo ello detenta en la determinación de la pena (Considerando Decimosexto).

En consecuencia, y siguiendo el razonamiento antes expuesto, cuando el sentenciador se enfrenta a las reglas previstas en el art. 21 debiera ya haber excluido de toda consideración a las agravantes mencionadas, lo que lleva a reubicar el ámbito donde podría reclamarse en este caso un error de derecho. En efecto, resulta igualmente relevante a los efectos del análisis de las resoluciones que son objeto de comentario en este artículo tener en cuenta que el vicio reclamado no radica en la conclusión concreta que el Tribunal acuerda sobre la procedencia de las circunstancias agravantes (es decir, en la discusión de fondo), sino más bien en la forma de aproximación que aplica la Corte para dar lectura a la remisión subsidiaria que contiene el art. 1 inc. 2 respecto a las 
"Fundamentación y determinación de la pena en el derecho penal de adolescentes. A propósito del juicio seguido contra B. N. M. por delito de robo con intimidación (RUC 0900505404-1) en la V Región"

normas generales del CP. Es ahí donde parece incurrir el Tribunal de instancia en un error de derecho, toda vez que asume que se trata de una remisión objetiva y automática, carente de la dimensión de sentido que establece la Ley 20.084.

De esta forma, el error al que apunta la recurrente no propone una cuestión atingente a la determinación de la pena, en concreto, a la aplicación de los arts. 21 de la Ley 20.084 y al 67 del CP (sin perjuicio de lo ya apuntado respecto a la falta de fundamentación), sino que se trata en el fondo de una cuestión que atañe a la determinación jurídica de los presupuestos de la responsabilidad, desarrollada en una modalidad que pareciera vulnerar el propio art. 1 inciso segundo de la Ley 20.084 (en base a que se hace una lectura meramente formal de su texto $)^{57}$.

Parece entonces que a este respecto ha sido mal planteado el propio recurso de nulidad pues, como señala la CS resolviendo la eventual ocurrencia de faltas o abusos disciplinarios, se trata de un recurso de derecho estricto, que sólo atribuye competencia al sentenciador para pronunciarse de los vicios invocados, los que en este caso apuntan de forma precisa a la normativa que se entiende erróneamente interpretada, esto es, los arts. 24 y 26 de la Ley $20.084^{58}$. Lo propio hubiere sido objetar directamente la consideración de las agravantes en atención a lo dispuesto en los caracteres básicos del modelo definido, fundamentalmente en los arts. 2 (en relación a los arts. 37 y 40 de la CIDN, por ejemplo), 20 y 44 de la Ley 20.084.

Con ello también parece que yerra el máximo Tribunal al entender que esta cuestión corresponde al ámbito de la determinación de la pena, que se habría podido tratar si la recurrente hubiere advertido un error de derecho en la apli-

${ }^{57}$ Si bien resultaría por ello objetable que se haya recurrido al inciso quinto del art. 67, esto es, que se haya operado como si concurrieren dos circunstancias agravantes y ninguna atenuante, ello no es sino consecuencia de una infracción precedente, constituyendo por ello solo una cuestión derivada.

${ }^{58}$ La falta o abuso en este caso habría consistido en que el Tribunal al acoger la causal de nulidad se habría referido a la procedencia de los arts. 456 bis $N^{\circ} 3$ y $12^{\circ} 16$ del Código Penal conforme a lo dispuesto en los arts. 21 y 23 de la Ley 20.084, a pesar de que el motivo invocado se referiría a una infracción de derecho relativa a la falta de aplicación de las pautas establecidas en los artículos 24 y 26 de la Ley $N^{\circ} 20.084$, causal en la que se [omite] toda referencia a los artículos 21 y 23 de este estatuto, en relación con los artículos 456 bis $N^{\circ} 3$ y $12 N^{\circ} 16$ del Código Penal". Estas serían las "únicas disposiciones que por referirse a la extensión temporal de la pena [...] otorgaban competencia a la Corte de Apelaciones para pronunciarse sobre la procedencia legal de las circunstancias agravantes de responsabilidad penal aplicables a este caso" no obstante que "las normas invocadas por el recurrente de nulidad dicen pertinencia con la ?naturaleza? de la pena a imponer al menor adolescente y a los límites relativos a la imposición de una sanción privativa de libertad, es decir a aquellas reglas atingentes al principio de diversificación o alternatividad de las sanciones, en virtud del cual, se le ofrece al juez no una pena única a elegir, sino que puede optar según las circunstancias del caso a penas diferentes, conforme a los criterios que el mismo legislador se encargó de entregarle en el artículo 24 de la Ley $N^{\circ} 20.084^{\prime \prime}$. Si bien volveremos sobre esta cuestión en breve anticipamos desde ya que lo resuelto en este caso no parece acertado sobre su propia lógica de razonamiento, toda vez que la causal invocada por la recurrente si pareciera abarcar el campo de aplicación de los arts. 21 a 23. 
cación de los arts. 21 a 23 de la Ley 20.084. La única posibilidad para ello sería entender que, con independencia del debate material acerca de la procedencia de las agravantes en atención a los caracteres propios de la adolescencia, hay otras razones en el propio art. 21 o en el 23 que impiden considerarlas. Sólo de esta forma se podría concebir una infracción de derecho en dicho contexto, esto es, si acorde a los propios contenidos de las normas que regulan la determinación legal de la pena se puede concluir que dichas agravantes deben ser excluidas.

A nuestro juicio se trata de una tesis llena de plausibilidad. Basta para ello con tener en cuenta el rol que cumple dicha disposición en el modelo, y particularmente en el proceso de determinación de la pena. Hemos ya advertido que el objetivo de la fase en que se inserta dicha disposición es determinar un quantum de aflictividad, medida o expresada en una pena de adultos. Dicha medida o quantum es la que permitirá identificar el tramo o marco compuesto por penas de adolescentes, momento en que recién empieza la tarea de determinación que es propia de la ley especial (sólo a partir de ese momento podemos razonar sobre penas de adolescentes). Las etapas previas (art. 21, esencialmente) tienen sentido en función de la proporcionalidad, objetivo que expresamente busca el legislador al regular el mecanismo. Sobre esta base -y como ya apuntamos- el sentido de la remisión a las reglas previstas "en el Párrafo 4 del Título III del Libro I del Código Penal, con excepción de lo dispuesto en el artículo 69 de dicho Código" que contiene dicha disposición es, concretamente, evitar que la pena de un adolescente pueda llegar a ser más gravosa que la de un adulto. Consecuentemente, la remisión a la aplicación de dichas reglas sólo debiera entenderse referida a casos en que a propósito de ello debiese tener lugar una reducción en la penalidad, pues sólo en dichos casos se genera el riesgo de desproporción relativa (adolescente/adulto). En los demás casos, esto es, si de la consideración de las normas deviene una agravación de la sanción, su aplicación carecería de fundamento. No hay que olvidar que en esta fase no estamos propiamente determinando la pena juvenil sino, exclusivamente, precisando un marco de alternativas de sanción acorde a la gravedad relativa del hecho punible.

Sobre esta base es perfectamente posible entender que en la aplicación de dicha normativa sólo deben considerarse las circunstancias atenuantes de responsabilidad penal concurrentes, sin perjuicio de que, posteriormente, el sentenciador tendrá oportunidad de hacerse cargo de las circunstancias agravatorias de la responsabilidad penal que sean procedentes de considerar, conforme a lo dispuesto en el art. 24 letra c), esto es, dentro del proceso de individualización de la pena adolescente.

Avala esta tesis la discusión que tempranamente se planteó en torno a la eventualidad de que el modelo de determinación de la pena previsto en la Ley 
"Fundamentación y determinación de la pena en el derecho penal de adolescentes. A propósito del juicio seguido contra B. N. M. por delito de robo con intimidación (RUC 0900505404-1) en la V Región"

20.084 incurriera en una doble consideración de las circunstancias agravantes de la responsabilidad (primero, en torno a la determinación legal, por aplicación del art. 21 y, luego, en la individualización, precisamente por lo dispuesto en el art. 24 letra c)), afectando con ello la prohibición de bis in idem ${ }^{59}$. Ello pues una explicación material de los roles que cumple cada etapa permite afirmar que el legislador no entendió que dichas circunstancias se encuentran incluidas en esta primera fase de la determinación de la pena, con lo cual quedaría salvado el problema de su potencial doble consideración en el propio diseño del modelo ${ }^{60}$.

Por último, es evidente que la explicación expuesta discurre en el entendido que el referente material del art. 21 es el denominado principio de proporcionalidad, esto es, aquella dimensión de dicho concepto que opera como criterio limitativo y de legitimidad de la intervención penal. A este respecto más de alguien podría llegar a compartir el argumento de base que hemos expuesto en lo relativo a entender que el referente propio de esta norma es precisamente la idea de proporcionalidad (sobre todo considerando que resulta indiscutible si se revisa la historia de la Ley 20.084) pero no coincidir con nosotros en cuanto a entender que el legislador se remite a una idea distinta de la proporcionalidad, precisamente, aquella que apunta a establecer una relación de equilibrio en las sanciones de ambos modelos. Se trata de una noción que esencialmente opera en la determinación de la pena y que es propia de dinámicas más bien centradas en ópticas retributivas de la sanción penal. Esta misma constatación hace altamente discutible que sea replicable su uso en un modelo que se encuentra reconocidamente regido por objetivos de carácter preventivo ${ }^{61}$. Lo dicho queda en evidencia si se tiene en cuenta que ambos sistemas (de adultos y de adolescentes) proponen mecánicas de determinación de sanciones completamente diversas, que por lo demás se encuentran regidas por criterios y objetivos perfectamente diferenciables ${ }^{62}$. Sobre esa base no se puede pretender exigir o conservar un paralelo entre las sanciones que promueva cada modelo, como se pretendería a través de esta dimensión positiva de la proporcionalidad.

\footnotetext{
${ }^{59}$ Bustos Ramírez, como en nota n. 14, pp. 64-5; Duran Migliardi, Mario: "Análisis político criminal de la Ley de Responsabilidad Penal adolescentes y sus modificaciones", en Estudios de Ciencias Penales. IV Jornadas de Derecho Penal y Ciencias Penales, Valdivia, 2007, p. 200; Horvitz L., como en nota n. 14, p. 113. También lo denuncia la Corte Suprema a través de un acuerdo del Tribunal pleno de 21 de Octubre de 2009 (p. 2).

${ }^{60}$ A la misma conclusión, si bien por razones que no son equivalentes, Ilega Medina Schulz, como en nota n. 6, pp. 212, 217 y 219 a 222; y VARGAS PINTO, como en nota n. 49, p. 485.

61 Al respecto Vid., por ejemplo, los arts. 20, 44, 52 y 53 de la Ley 20.084, entre otros.

${ }^{62}$ Al respecto baste ver las finalidades concretas de la sanción penal juvenil descritas en el art. 20 de la Ley.
} 
$Y$ es que resulta indiscutible que las disposiciones relativas a la determinación de la pena dan cuenta de que el legislador no estaría siguiendo en ambos casos una misma orientación, ni sería por ello sustentable que pretendiera alcanzar o respetar dicho equilibrio abstracto entre las sanciones procedentes bajo ambos sistemas.

\section{A MODO DE CONCLUSIÓN}

Creemos, en consecuencia, en lo relativo a lo resuelto en este caso, que el Tribunal de instancia ha errado tanto en la fundamentación de la determinación de la pena como en la aplicación del derecho, esto último, en relación con la aplicación de las agravantes previstas en los arts. $12 \mathrm{~N}^{\circ} 16$ y 456 bis $\mathrm{N}^{\circ} 3$ del CP. Sin embargo, y por defectos atribuibles al recurso deducido, sólo la primera de dichas alegaciones podría haber sido acogida como cuestión de nulidad, y no sólo en atención a que se disponen las causales en forma subsidiaria. El motivo de fondo radica en que el error de derecho denunciado (consistente en no excluirlas de consideración por razones asociadas a los caracteres especiales del modelo previsto en la Ley 20.084) radicaría en disposiciones legales diversas a las que han sido citadas para fundamentar el recurso o, en su caso, debiera haberse objetado directamente la posibilidad de que en la aplicación del art. 21 debieran considerarse las circunstancias agravantes de responsabilidad, en atención a que su fundamento material radica en la pretensión de conservar la proporcionalidad relativa de las sanciones de adolescentes respecto de las aplicables a un adulto por los mismos hechos.

\section{ExCurso: Sentencia de la exCMA. Corte suprema}

No quisiéramos finalizar sin antes hacer presente tres consideraciones que recaen sobre el proceder adoptado por la Corte Suprema en este caso.

En primer lugar hay que indicar que las facultades disciplinarias a las que alude el máximo Tribunal se originan en la presentación de un recurso de queja por parte del Ministerio Público, recurso que correctamente fue declarado inadmisible por el mismo Tribunal. Sin embargo, lo relevante es que la Corte a pesar de ello pasa igualmente a conocer de las faltas o abusos denunciados actuando de manera oficiosa, procedimiento que si bien se ampara en el uso de facultades disciplinarias generales es, en los hechos, plenamente contradictorio con la propia inadmisibilidad que ha declarado. Es conocida la crítica que subyace a la posibilidad de que los Tribunales Superiores de Justicia se puedan abocar al conocimiento de resoluciones dictadas por los Tribunales inferiores usando el expediente de sus facultades disciplinarias, equiparando en la práctica las diferencias de criterio presentes en la administración jurisdiccional con faltas o abusos de ejercicio que operan mas bien en el ámbito funcionario. Dicha equi- 
"Fundamentación y determinación de la pena en el derecho penal de adolescentes. A propósito del juicio seguido contra B. N. M. por delito de robo con intimidación (RUC 0900505404-1) en la V Región"

paración se traduce normalmente en la posibilidad de que el Tribunal Superior modifique lo resuelto en uso de potestades administrativas bajo el entendido que dichas resoluciones constituyen el resultado de una conducta impropia que debe ser corregida en dicho ámbito (disciplinario). Lo confirma el que es usual en estos casos que a pesar de que se da por establecida la responsabilidad disciplinaria el único efecto asociado a los abusos y faltas cometidas es la modificación de la resolución adoptada, sin que se impongan las sanciones que debieran emanar de la constatación de un comportamiento indebido, ni se arbitren o dispongan los medios tendientes a ello. Y este caso no hace excepción. En concreto, la Corte Suprema modifica lo resuelto, invalidando la decisión recaída en el recurso de nulidad deducido, bajo el entendido que en la dictación de dicha resolución se ha incurrido en faltas o abusos graves sin remitir, a pesar de ello, los antecedentes al pleno para que arbitre las sanciones disciplinarias correspondientes.

Pero además de ello de la sola lectura de las resoluciones citadas parece claro que yerra el máximo Tribunal en cuestiones de hecho a la hora de adoptar esta resolución. En efecto, y como señalamos, considera constitutivos de falta y abuso grave el hecho que los Ministros que integran la sala de la Corte de Apelaciones de Valparaíso hubieren acogido la causal subsidiaria planteada por la recurrente a partir de un análisis que excedería los presupuestos que se esgrimieron para su respaldo, sobrepasando con ello el límite de su competencia en forma indebida. Además, se sumaría a ello el que al resolver la improcedencia de la agravante prevista en el $n^{\circ} 3$ art. 456 bis del CP habrían modificado lo resuelto por el Tribunal de instancia en un ámbito que le es privativo, esto es, el de establecer el supuesto fáctico que servirá de base para resolver. Se funda en que, por el hecho de considerar que "no hay evidencias que señalen que [se] buscó la compañía de otro para obtener ventajas sobre la víctima y lograr su propósito que no era otro que apropiarse de cosa mueble ajena sin la voluntad de su dueño. El otro sujeto, era sólo su compañero natural, como pudo haber sido cualquiera otra persona, con el cual caminaba, sin otro propósito que comprar bebidas" a los efectos de rechazar la aplicación de la agravante respectiva. Dicho razonamiento alteraría los hechos que fueron legítimamente determinados por el Tribunal de instancia, constituyendo un proceder indebido.

Sobre la primera de estas cuestiones hay que recordar que la Corte de Apelaciones conoció de dos causales de nulidad. La primera de ellas -desestimada- se fundaba en la insuficiente fundamentación del Tribunal a quo, basada en que no se consideraron los criterios de determinación de pena previstos en los arts. 24 y 26 de la Ley 20.084. La segunda, por su parte, de carácter subsidiario, se fundaba en una errónea aplicación del derecho que tiene lugar en cuanto el Tribunal de instancia procede a regular la pena sin considerar los caracteres especiales propios y definitorios de la Ley 20.084 , aludiendo para ello a las 
Ilamadas reglas de (sic) Beijin y a los criterios establecidos en el art. 24. En este caso, el Tribunal habría excedido el marco de sus competencias pues, en base a lo planteado por la recurrente habría procedido a desestimar la aplicación de circunstancias agravantes, cuestión a debatir a la hora de resolver la denominada fase primaria de la determinación de la pena, regulada en los arts. 18 al 22 (conforme al criterio del máximo Tribunal).

De esta forma a partir del hecho de considerar que la causal subsidiaria opera precisamente sobre el debate que proponen los artículos 21 y 23, en relación con los artículos 456 bis № 3 y $12 N^{\circ} 16$ del CP es que la Corte Suprema estima que se ha excedido la competencia concedida, pues la recurrente sindicó como fuente de su alegación el contenido del art. 24 y no las disposiciones antes mencionadas.

El asunto es que la recurrente objeta la consideración de los criterios previstos en el art. 24 (y del 26, más allá que a estos efectos ello no resulte relevante) a través de todo el proceso de determinación de la pena adolescente, lo que se extiende tanto a las normas relativas a la individualización (arts. 23 y 24) como a aquellas que afectan a la denominada fase primaria de la determinación de la pena. De esta forma no parece que sea acertado o verdadero el supuesto sobre el que opera para estimar que concurre una falta o abuso, sobre la propia lógica que sostiene la Corte Suprema (esto es, que el tema resuelto se trata en los arts. 21 y 23).

Asimismo en la segunda de estas cuestiones tampoco parece acertar el máximo Tribunal. El que la Corte de Apelaciones haya estimado que el hecho que B. N. haya actuado en compañía de Luis Araya es una cuestión circunstancial en el contexto del ilícito cometido, considerando como una cuestión basal el "que es propio de los adolescentes desarrollar su cotidianeidad junto a otro u otros sujetos", constituye una afirmación que no contradice la base fáctica determinada por el Tribunal a quo y que se puede sintetizar en una descripción propia de la coautoría donde ambos intervinientes participan ejecutivamente de la comisión del delito. La cuestión es que al resolver la nulidad el Tribunal se mueve en el ámbito de la interpretación o subsunción donde dicha base fáctica es analizada en función del contexto normativo que propone el $\mathrm{N}^{\circ} 3$ del art. 456 bis del CP, ámbito que se ubica muy lejos del plano de la acreditación de los hechos. Es sólo este último el que resulta privativo y propio del Tribunal de instancia, facultad que aparece incluso hoy en día reforzada en nuestro ordenamiento vigente a partir de la vigencia real del principio de inmediación, como señala acertadamente el máximo Tribunal.

La cuestión, sintéticamente, es que no se alteran en modo alguno los hechos que se dan por acreditados, presentándose en forma análoga en ambas resoluciones. $Y$ es que una cosa es valorar los antecedentes probatorios para determinar qué fue lo que ocurrió (al menos en términos procesales) y otra 
muy diversa es preciar cuáles son las implicancias jurídicas que dichos hechos motivan, esto es, valorar sus efectos acorde a lo prescrito en las disposiciones jurídicas pertinentes a partir de la lectura de los hechos que el Tribunal realice. $Y$ en dicho contexto una lectura distinta no es equivalente a una modificación de los hechos. Es precisamente en este último plano en el que se mueve la Corte de Apelaciones cuando califica el sentido que en su concepto tiene para el derecho el actuar conjunto de ambos intervinientes, lo que se puede apreciar en el solo hecho que dicha resolución no niega ni rechaza en modo alguno el que tanto B. N. como Luis Araya participaron en la ejecución del delito. Es el significado jurídico de dicha participación conjunta el que resulta valorado en forma diversa, lo que se mueve en el ámbito de la subsunción, adscripción normativa o, si se prefiere (en términos más tradicionales), calificación jurídica de dichos hechos.

De ahí que no sea tampoco efectivo que dicho proceder sea constitutivo de una falta o abuso, con lo cual, resultan del todo discutibles los motivos aludidos para invalidar lo resuelto. 
